\title{
Stimulation of Porcine Jejunal lon Secretion In Vivo by Protein Kinase-C Activators
}

Cynthia S. Weikel, Julianne J. Sando, and Richard L. Guerrant

Divisions of Geographic Medicine and Infectious Diseases, Departments of Medicine and Pharmacology,

University of Virginia School of Medicine, Charlottesville, Virginia 22908

\begin{abstract}
Microbial toxins act through cyclic nucleotide dependent (cAMP or cGMP) or cyclic nucleotide independent pathways to cause intestinal ion secretion. To explore the calcium dependent, cyclic nucleotide independent pathway that is postulated to involve protein kinase $C$ activation, we measured protein kinase $C$ activity and phorbol ester binding in isolated intestinal epithelial cells and examined the effects of the $\mathbf{C}$-kinase activators, phorbol myristate acetate, phorbol dibutyrate, and 4- $\beta$-phorbol-12,13didecanoate, in weaned pig jejunum in vivo. We demonstrated both protein kinase $\mathbf{C}$ activity and specific phorbol ester binding in porcine jejunal epithelial cells. Phorbol myristate acetate, phorbol dibutyrate, and 4- $\beta$-phorbol-12,13-didecanoate $\left(10^{-5} \mathrm{M}\right)$ each caused striking secretory responses at $5 \mathrm{~h}$ with accumulation of $\mathrm{Na}^{+}, \mathrm{K}^{+}, \mathrm{Cl}^{-}$, and $\mathrm{HCO}_{3}^{-}$intraluminally. In contrast, 4- $\alpha-$ phorbol and 4- $\alpha$-phorbol-12,13-didecanoate, which do not affect protein kinase $C$, allowed normal net absorption of all electrolytes from the intestinal lumen equivalent to controls with only Ringer's lactate. Time course studies revealed significant secretion within 30 min after exposure to the $\mathrm{C}$-kinase activators. These data suggest an important role for protein kinase $\mathbf{C}$ activation in intestinal ion secretion.
\end{abstract}

\section{Introduction}

Four distinct pathways may be involved in intestinal ion secretion stimulated by bacterial toxins. The first two pathways are cyclic nucleotide-dependent: the activation of adenylate cyclase by choleratoxin and the heat-labile enterotoxin of Escherichia coli, and the activation of guanylate cyclase by the heat-stable enterotoxin (STa) of $E$. coli (1). Two cyclic nucleotide independent pathways have been receiving increasing attention in recent years. First is the secretion stimulated by the second heat-stable enterotoxin of $E$. coli, STb, the mechanism of action of which is unknown but does not involve activation of adenylate or guanylate cyclase (2). Second is the cyclic nucleotide independent secretion stimulated by a calcium dependent pathway. Two pools of calcium are recognized as important in intestinal secretory

This work was presented in part at the American Federation of Clinical Research Meetings, Washington, DC, 1985. Address reprint requests to Dr. Weikel, Division of Geographic Medicine, University of Virginia School of Medicine, Box 485, Charlottesville, VA 22908.

Received for publication 7 June 1985.

J. Clin. Invest.

(C) The American Society for Clinical Investigation, Inc.

0021-9738/85/12/2430/06 \$1.00

Volume 76, December 1985, 2430-2435 processes. Certain intestinal secretagogues have been shown to have a secretory effect that is dependent on extracellular calcium (calcium ionophore A23187 [3, 4], acetylcholine [3, 5], Clostridium difficile enterotoxin [6], and serotonin [7]). Other agents cause secretion that is dependent, in part, on intracellular pools of calcium as in secretion stimulated by the cyclic nucleotide dependent pathways $(1,8,9)$.

Several authors $(10,11)$ have postulated a role for protein kinase $\mathrm{C}(\mathrm{PK}-\mathrm{C})^{1}$ in the stimulation of intestinal secretion, but no data showing an association between intestinal secretion and PK-C stimulation have been reported. PK-C stimulation has been shown to have a crucial role in signal transduction for a wide variety of secretory processes such as epinephrine secretion by the adrenal medulla, amylase secretion by pancreatic acinar cells, insulin secretion by pancreatic islets (12), and parathyroid hormone secretion (13). These secretory processes are initiated by the signal-dependent breakdown of inositol phospholipids that release diacylglycerol. Diacylglycerol has been shown to increase the affinity of PK-C for calcium, and, in the presence of acidic phospholipids, such as phosphatidylserine (PS), leads to full activation of this enzyme (14). Furthermore, PK-C has been shown to be widely distributed in nature (15), and recently, de Jonge (16) has reported the presence of phospholipid-stimulatable protein kinase activity (presumably PK-C) in isolated brush border membranes of rat small intestine.

The purposes of this study were to determine whether PK$C$ activity was detectable in intestinal epithelial cells and to evaluate whether stimulation of PK-C can cause net intestinal ion secretion in vivo. To evaluate this latter possibility we used the phorbol esters. The phorbol esters have been demonstrated to bind to PK-C and to substitute for diacylglycerol in the stimulation of PK-C without changing intracellular calcium concentrations $(14,17)$. We report that both PK-C activity and specific phorbol ester binding are present in isolated porcine intestinal epithelial cells. Furthermore, the beta (active) analogues of the phorbol esters stimulate ion secretion in piglet jejunum in vivo, while the alpha analogues, which have no biological activity and do not bind to PK-C, do not cause secretion. These results suggest an important role for PK-C stimulation in intestinal ion secretion.

\section{Methods}

Materials. Two beta phorbol esters, phorbol myristate acetate (PMA) and phorbol dibutyrate (PDB), were obtained from Consolidated Mid-

1. Abbreviations used in this paper: 4- $\alpha$ (or $\beta$ )-PDD, 4- $\alpha$ (or $\beta$ )-phorbol12,13-didecanoate; PDB, phorbol dibutyrate; PK-C, protein kinase C; PMA, phorbol myristate acetate; PS, phosphatidylserine; PSP, phenolsulfonphthalein. 
Line Corp. (Brewster, New York). 4- $\beta$-phorbol-12,13-didecanoate (4- $\beta$ PDD), 4- $\alpha$-phorbol-12,13-didecanoate (4- $\alpha$-PDD), and 4- $\alpha$-phorbol were obtained from Sigma Chemical Co. (St. Louis, MO). Stock solutions of phorbol esters $\left(10^{-3} \mathrm{M}\right)$ were stored in absolute ethanol at $-15^{\circ} \mathrm{C}$ until use. For injection into ligated intestinal segments, the phorbol esters were diluted in Ringer's lactate, $\mathrm{pH} 7.4$, containing $1 \%$ bovine serum albumin (BSA) (Sigma Chemical Co.). Control solutions containing Ringer's lactate, an equivalent amount of alcohol without the phorbol esters, and 1\% BSA were run as paired controls in all experiments. The Ringer's lactate contained sodium (125 mM), potassium $(4.7 \mathrm{mM})$, magnesium (1.2 mM), calcium (1.25 mM), chloride (127 mM), bicarbonate $(25 \mathrm{mM})$, and sulfate $(1.2 \mathrm{mM})$.

Cell isolation, rupture, and fractionation. Intestinal epithelial cells were isolated from the jejunum of 4-6-wk-old weaned piglets from a single supplier (Pagebrook Farm, Gordonsville, VA) using the methods of Weiser (18) or Kimmich (19). Approximately $10^{8}$ cells or more were obtained with $\geq 80 \%$ viability as determined by trypan blue exclusion. Cells were ruptured in $2-10 \mathrm{ml}$ of homogenization buffer $(20 \mathrm{mM}$ Tris, pH 7.5, $0.33 \mathrm{M}$ sucrose, $2 \mathrm{mM}$ EDTA, $0.5 \mathrm{mM}$ EGTA, $0.5 \mathrm{mM}$ benzamidine, and $25 \mu \mathrm{g} / \mathrm{ml}$ leupeptin) with 35 strokes in a Dounce homogenizer fitted with a tight glass pestle. Cytosol fractions were prepared by centrifuging for $45 \mathrm{~min}$ at $105,000 \mathrm{~g}$ and stored at $-70^{\circ} \mathrm{C}$ until use.

Protein kinase assay. Calcium/phospholipid-dependent protein kinase activity was assayed by incubation at $30^{\circ} \mathrm{C}$ for $3 \mathrm{~min}$ in a $150 \mu \mathrm{l}$ reaction

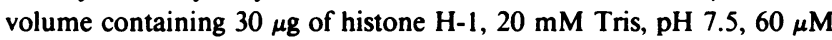
$\mathrm{CaCl}_{2}, 5 \mathrm{mM}$ magnesium acetate, $100 \mu \mathrm{M}$ ATP, 75-130 Ci/M [ $\gamma$ $\left.{ }^{32} \mathrm{P}\right] \mathrm{ATP}$, and $60 \mu \mathrm{l}$ of cytosol enzyme (containing 8-50 $\mu \mathrm{g}$ protein) with or without $6 \mu \mathrm{g}$ of PS and $0.25 \mu \mathrm{g}$ of diolein as indicated. The phospholipid and diolein were added from a stock solution prepared just before use by evaporating aliquots of PS $(10 \mathrm{mg} / \mathrm{ml})$ and diolein $(1 \mathrm{mg} / \mathrm{ml})$ under nitrogen gas and sonicating in $2 \mathrm{ml}$ of $20 \mathrm{mM}$ Tris, $\mathrm{pH} \mathrm{7.5}$. Reactions were initiated by addition of the reaction mixture and terminated by pipetting $75 \mu$ l of the reaction volume onto Whatman P81 cellulose phosphate paper (Fisher Scientific Products, Springfield, NJ). Filter papers were washed three times in $50 \mathrm{mM} \mathrm{NaCl}$, dried, and counted for radioactivity.

Phorbol ester binding assay. Phorbol ester binding was assayed on cytosolic fractions ( $360 \mu$ l containing $24-150 \mu \mathrm{g}$ protein) by incubation for $2-20 \mathrm{~h}$ at $4^{\circ} \mathrm{C}$ in a $500 \mu 1$ reaction volume containing $20 \mathrm{mM}$ Tris, pH 7.5, $75 \mathrm{mM}$ magnesium acetate, $0.5 \mathrm{mM} \mathrm{CaCl}_{2}, 1.2 \mathrm{mg} / \mathrm{ml} \mathrm{BSA}$, $96 \mu \mathrm{g} / \mathrm{ml} \mathrm{PS}, 4 \times 10^{-8} \mathrm{M}\left[{ }^{3} \mathrm{H}\right] \mathrm{PDB}$, and either vehicle (total binding) or $3 \mu \mathrm{M}$ unlabeled PDB or PMA (nonspecific binding). Bound $\left[{ }^{3} \mathrm{H}\right] \mathrm{PDB}$ was separated from free $\left[{ }^{3} \mathrm{H}\right] \mathrm{PDB}$ by filtering the mixture through 2.4$\mathrm{cm}$ Whatman glass microfibre filters (Fisher Scientific Products) by suction. The tubes and filters were washed five times with ice-cold phosphatebuffered saline and the filters were counted for radioactivity.

Partial purification of cytosolic PK-C. PS affinity column chromatography was used to partially purify cytosolic PK-C. The column resin was prepared according to the method of Uchida and Filburn (20) as follows: Cholesterol $(50 \mathrm{mg}$ ) and PS (10 $\mathrm{mg}$ in chloroform) were dried under $\mathrm{N}_{2}$ gas and dissolved in absolute ethanol $(1 \mathrm{ml})$ in a boiling water bath. A warm solution of $15 \%$ acrylamide and $5 \%$ bis $(10 \mathrm{ml})$ was added and polymerized with the addition of $10 \%$ ammonium persulfate $(0.3$ $\mathrm{ml}$ ) and $N, N, N^{\prime}, N^{\prime}$ tetramethylethylenediamine (TEMED) $(5 \mu \mathrm{l})$. The gel was stored in the dark, at room temperature, overnight, to ensure complete polymerization, and later stored at $4^{\circ} \mathrm{C}$ until used. The polymerized gel resin was then minced into small pieces and homogenized (4-6 strokes) in 20-30 $\mathrm{ml}$ of water using a loose-fitting Dounce homogenizer. The homogenized gel resin was defined 3-4 times, packed into a column $(1.6 \times 5 \mathrm{~cm})$, and equilibrated in $200 \mathrm{mM} \mathrm{KCl}, 1 \mathrm{mM} \mathrm{CaCl}$, $50 \mathrm{mM} 2$-mercaptoethanol, $0.5 \mathrm{mM}$ benzamidine, $25 \mu \mathrm{g} / \mathrm{ml}$ leupeptin, and $5 \mathrm{mM} 2\left[\mathrm{~N}\right.$-morpholino]ethane-sulfonic acid (MES), pH 6.5 , at $4^{\circ} \mathrm{C}$.

Cytosol was loaded in the presence of $5 \mathrm{mM} \mathrm{CaCl}_{2}$ onto the PS affinity resin for $45 \mathrm{~min}$ at $4^{\circ} \mathrm{C}$ using a vertical rotator to maintain the suspension. The resin was loaded into the column and washed successively with three column volumes each of the $5 \mathrm{mM}$ MES buffer described above with either $1 \mathrm{mM} \mathrm{CaCl}_{2}, 0.1 \mathrm{mM} \mathrm{CaCl}_{2}$, or $2 \mathrm{mM} \mathrm{EGTA}$ in place of the calcium. Portions of the resulting affinity column fractions were immediately stabilized with the addition of ovalbumin $(1 \mathrm{mg} / \mathrm{ml})$. Selected column fractions were subsequently assayed for protein kinase activity and phorbol ester binding as described above. For the protein kinase assay, fractions were desalted over Sephadex G-25.

Intestinal loop assays. For these studies, 4-6-wk-old weaned piglets were used. Ligated porcine intestinal segments ( $\sim 6-\mathrm{cm}$ jejunal segments) were injected with $5 \mathrm{ml}$ of the test substance. At $5 \mathrm{~h}$ the fluid was removed from the segments and assayed for electrolyte content using a sequential multiple analyzer with computer (Technician Instruments, Tarrytown, NY), and volume and length of the segment were measured. These results were compared with the electrolyte content of the preinoculation solutions measured the same way. In some experiments, the segments were exposed to the test substances for $30 \mathrm{~min}$ and $16 \mathrm{~h}$. Portions of the experimental and control intestinal segments were fixed in $10 \%$ formalin, and subsequently the histology was evaluated by hematoxylin and eosin staining.

Time course studies. For these experiments, ligated porcine intestinal segments $(\sim 12-\mathrm{cm}$ jejunal segments) were cannulated with multiperforated feeding tubes (eight French; Argyle, Div. Sherwood Medical, St. Louis, MO). Each segment was washed until clear with $15-\mathrm{ml}$ vol of Ringer's lactate. Challenge solutions consisted of Ringer's lactate, $\mathbf{p H}$ 7.4, with $1 \%$ BSA, and the nonabsorbable volume marker phenolsulfonphthalein (PSP, $50 \mathrm{mg} /$ liter) with $10^{-5} \mathrm{M}$ PMA, PDB, 4- $\alpha$-phorbol, or alcohol. Net water fluxes were measured during consecutive 30-min periods. Measurement of flux during a 30 -min period was initiated by instillation of $15 \mathrm{ml}$ of a challenge solution. After mixing, $1 \mathrm{ml}$ was withdrawn as the initial sample. 1-ml samples were then taken after mixing at 30,60, and $90 \mathrm{~min}$. At $90 \mathrm{~min}$, the segments were emptied, washed three times with $15 \mathrm{ml}$ of Ringer's lactate, and refilled with 15 $\mathrm{ml}$ of Ringer's lactate with $1 \%$ BSA and PSP $(50 \mathrm{mg} / \mathrm{liter})$ without additional phorbol esters. Samples were taken as described for an additional $90 \mathrm{~min}$.

The initial and final samples were analyzed for PSP concentration colorimetrically by the method of Allen (21). To determine the net water flux for each study period, initial and final volumes were calculated for each segment using the equation $V_{1} C_{1}=V_{2} C_{2}$. $V_{1}$ and $V_{2}$ represent the initial and final volumes, respectively, for each study period. Similarly, $C_{1}$ and $C_{2}$ represent the initial and final concentrations of PSP for each study period. Net water flux $=V_{2}-V_{1}$ (expressed as microliters per centimeter jejunum per minute).

Statistical methods. Data are expressed as mean \pm SEM. All statistical comparisons were done using the $t$ test or, where appropriate, the paired $t$ test.

\section{Results}

To investigate a potential role for $\mathrm{PK}-\mathrm{C}$ in intestinal ion secretion, we first verified the existence of $\mathrm{PK}-\mathrm{C}$ in jejunal epithelium. Cytosolic preparations (frozen at $-70^{\circ} \mathrm{C}$ ) from three different piglets exhibited a phospholipid-stimulatable kinase activity of $2.25 \pm 0.62$ pmol phosphate incorporation into histone $\mathrm{H}-1$ per milligram cytosol protein per $3 \mathrm{~min}$. Additional experiments ( $n$ $=2$ ) measuring PK-C enzymatic activity on fresh and frozen cytosols from the same piglet indicated that $\sim 20 \%$ of the phospholipid-stimulatable kinase activity was destroyed by freezing at $-70^{\circ} \mathrm{C}$. PK-C also serves as the receptor protein for the tumorpromoting phorbol esters $(14,17)$, the most potent and widely used activators of PK-C. To further establish the identity with PK-C of the phospholipid-stimulatable kinase activity in cytosol of porcine jejunal epithelial cells, the enzyme was partially purified by PS affinity chromatography. Both enzyme and phorbol ester binding activities were monitored. Fig. 1 shows that specific PDB binding activity co-eluted with the phospholipid-stimulatable kinase activity in the presence of $2 \mathrm{mM}$ EGTA as previously described (20). 

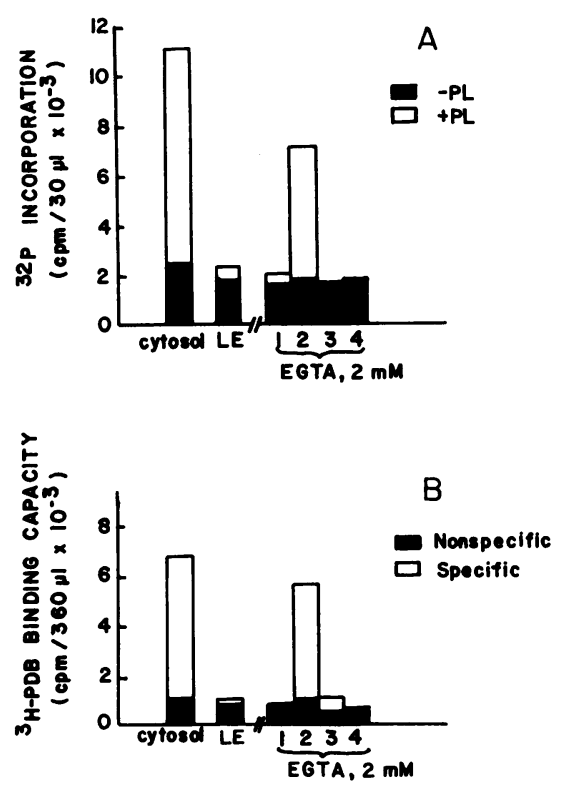

Figure 1. (A) PK-C enzymatic activity. ${ }^{32} \mathrm{P}$ incorporation into a histone $\mathrm{H}-1$ substrate was measured on whole cytosol, and on the loading eluant (LE) and 4 cytosolic fractions eluted with 2 mM EGTA from a PS affinity column. The open bars represent the specific phospholipidstimulatable PK-C enzymatic activity. Data are means of duplicate measurements from a representative experiment repeated once. $(B)$ Phorbol ester binding capacity. PDB binding was measured in the presence of vehicle (total binding) or $3 \mu \mathrm{M}$ unlabeled PDB or PMA (nonspecific binding) on whole cytosol, loading eluant and cytosolic fractions as for the PK-C enzymatic activity. The open bars represent the specific phorbol ester binding. Data are means of duplicate measurements from a representative experiment repeated once.

The effect of PMA and PDB on ion secretion in porcine jejunum in vivo was then tested. Both PMA and PDB were found to cause a dose-dependent increase in the volume/length ratios measured in the intestinal segments at $5 \mathrm{~h}$ (Fig. 2). By paired analysis, significant secretion was first seen at a concentration of $10^{-6} \mathrm{M}$ for PMA $(P \leq 0.01)$ and PDB $(P \leq 0.03)$, and was maximal by $10^{-5} \mathrm{M}$. Intestinal segments treated with either the Ringer's lactate control or 4- $\alpha$-phorbol $\left(10^{-5} \mathrm{M}\right)$ did not show significant secretion. Comparison of the active and inactive analogues of phorbol-12,13-didecanoate (Fig. 3) gave volume/ length ratios of $0.54 \pm 0.2$ and $0.07 \pm 0.2$, respectively $(P<0.0001)$.

The time course of the phorbol ester effect on the net jejunal water flux is depicted in Fig. 4. After only $30 \mathrm{~min}$ exposure of the jejunal mucosa to PMA or PDB, significant $(P \leq 0.03)$ secretion compared with the 4- $\alpha$-phorbol control was detected. Significant secretion persisted at all subsequent time points $(P$ $\leq 0.01$ for PMA or PDB vs. controls). In contrast, the Ringer's lactate and 4- $\alpha$-phorbol controls allowed normal net water absorption to occur.

Summarized in Table I are the effects of the $\beta$ and $\alpha$ phorbol esters on the intestinal fluid electrolyte content after $5 \mathrm{~h}$ of incubation. Results with the 4- $\alpha$-phorbol and 4- $\alpha$-PDD were combined because they affected electrolyte movement in an identical fashion. In addition, the intestinal fluid electrolyte content of segments treated only with Ringer's lactate did not differ from those treated with the phorbol esters. In our system, comparison of the $\beta$ phorbol esters to the $\alpha$ compounds revealed significant net accumulation of all electrolytes measured $(P \leq 0.004)$ except

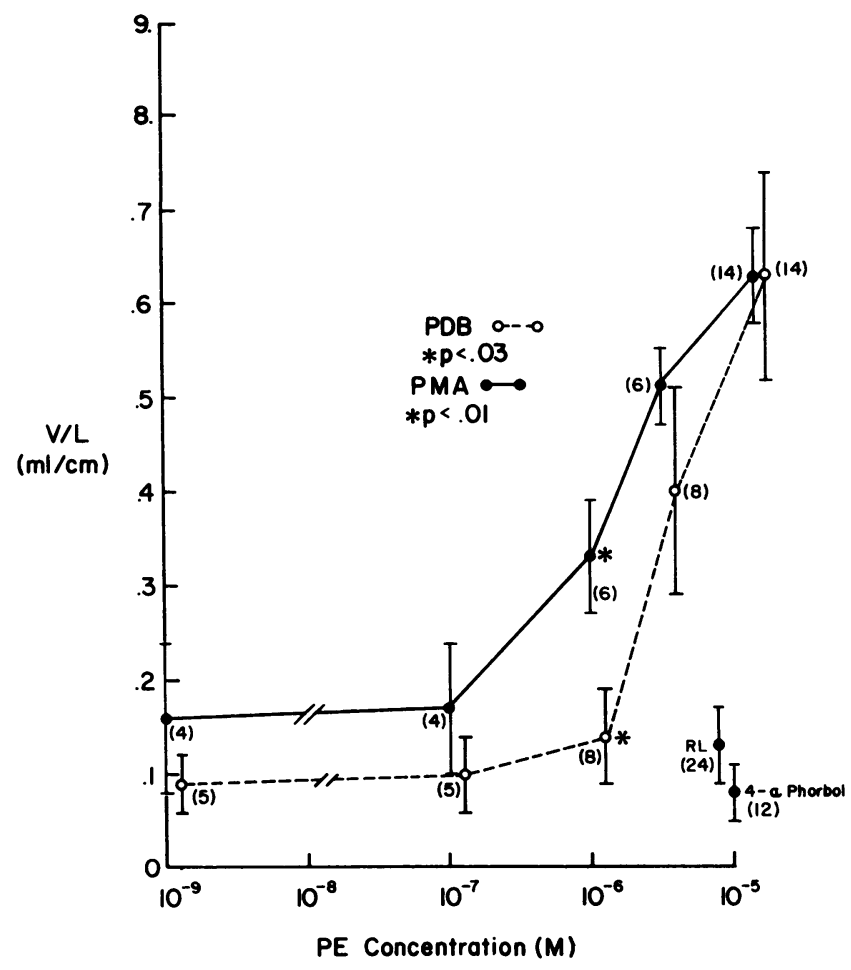

Figure 2. Phorbol ester (PE) concentration dependency for the effect of PMA and PDB on fluid secretion in porcine jejunum in vivo. Secretion was measured as the volume/length ratios $(\mathrm{V} / \mathrm{L}$, milliliters per centimeter). Segments $(n)$ in 2-11 pigs. Data are expressed as mean \pm SEM for $n$ segments.

for the $\mathrm{HCO}_{3}^{-}$of $4-\beta-\mathrm{PDD}(P \leq 0.04)$. In other systems, the phorbol esters exhibit a rigid structure activity relationship (22), with PMA being the most potent and $4-\beta$-PDD being the least potent of the three we have examined. In our system, comparison of the effects of the individual beta analogues on the electrolyte content of the intestinal fluid revealed a differential effect on sodium, potassium, and chloride, with PDB being most potent and $4-\beta$-PDD least potent. In contrast, bicarbonate was affected similarly by all three beta analogues. One possibility for the apparent increased potency of PDB with respect to PMA is the much greater lipophilicity of PMA. Because of intestinal nonspecific binding of PMA (23), its free concentration is probably much less than that of PDB.

Lastly, we evaluated the effect of the phorbol esters on histology. Neither the Ringer's lactate control nor the alpha analogues caused any abnormality in jejunal histology. Although a slight increase in epithelial cells was seen in the lumen at $30 \mathrm{~min}$ with the beta analogues, there was no inflammatory infiltrate.

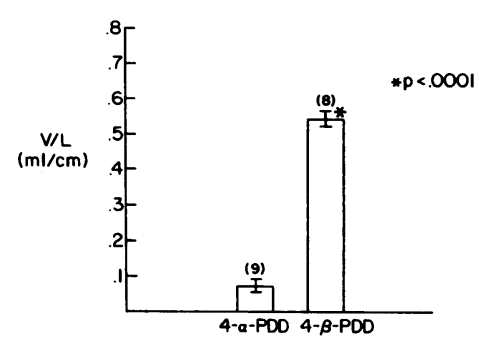

Figure 3. The effect of 4- $\beta$ and 4- $\alpha$-PDD $\left(10^{-5} \mathrm{M}\right)$ on fluid secretion in porcine jejunum in vivo. Secretion was measured as the volume/length ratios $(\mathrm{V} / \mathrm{L}$, milliliters per centimeter) of intestinal segments $(n)$ in three piglets. Data are expressed as mean \pm SEM for $n$ segments. 


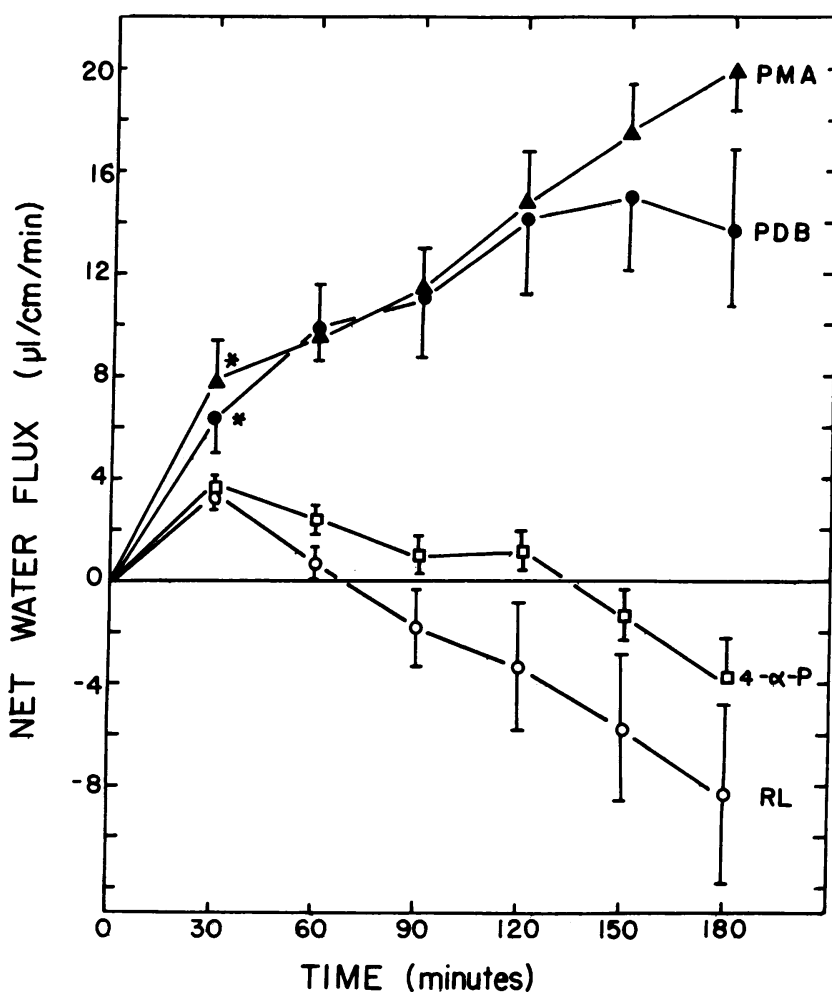

Figure 4. The time course of the effect of 4- $\alpha$-phorbol, PMA, and PDB $\left(10^{-5} \mathrm{M}\right)$ on the net water flux in porcine jejunum in vivo. Intestinal secretion (expressed as microliters per centimeter per minute) was measured in three piglets using the nonabsorbable volume marker, PSP (50 mg/liter). Significant secretion was detected at 30 min with both PMA and PDB $(P \leq 0.03)$ compared with the 4- $\alpha$ phorbol control. Data are expressed as mean \pm SEM.

A transient, minimal increase in the number of polymorphonuclear leukocytes in the lamina propria was seen in the small bowel only at $5 \mathrm{~h}$. At $16 \mathrm{~h}$, secretion persisted with no histologic abnormalities. Although the phorbol esters are not chemotactic for neutrophils, these compounds do stimulate release of lysosomal enzymes, which are chemotactic and may account for the mild transient accumulation of polymorphonuclear leukocytes noted in these studies. The fact that mepacrine, a phos-

Table I. Effect of Alpha and Beta Phorbol Esters (PE) on Net Intestinal Fluid Electrolyte Content (X士SEM)

\begin{tabular}{lcccc}
\hline & $\mathrm{Na}^{+}$ & $\mathrm{K}^{+}$ & $\mathrm{Cl}^{-}$ & $\mathrm{HCO}_{3}^{-}$ \\
\hline$\beta$-PE $\ddagger$ & & & & \\
PDB & $138 \pm 3$ & $10.2 \pm 2$ & $115 \pm 18$ & $12 \pm 3$ \\
PMA & $93 \pm 13$ & $6.5 \pm 1$ & $82 \pm 12$ & $9 \pm 1$ \\
$4-\beta$-PDD & $76 \pm 8$ & $5.3 \pm 0.3$ & $54 \pm 4$ & $12 \pm 6$ \\
$\alpha$-PE $\S$ & $27 \pm 3$ & $3.2 \pm 0.2$ & $26 \pm 3$ & $1 \pm 0.5$ \\
Ringer's lactate & $41 \pm 16$ & $2 \pm 1$ & $39 \pm 15$ & $3 \pm 2$ \\
\hline
\end{tabular}

* Electrolytes in microequivalents per centimeter.

$\ddagger P \leq 0.004$ for all $\beta$-PE for each ion, compared with $\alpha$-PE except for $\mathrm{HCO}_{3}^{-}$of 4- $\beta$-PDD $(P \leq 0.04)$.

$\S$ Includes 4- $\alpha$-phorbol and 4- $\alpha$-PDD.

Electrolytes were measured on fluid removed from ligated intestinal segments after $5 \mathrm{~h}$ of incubation with the specified phorbol ester or Ringer's lactate. pholipase $A_{2}$ inhibitor, did not reduce the secretory response to PMA, further argues against a role for neutrophils in the secretory response observed. The volume/length ratio in ligated intestinal segments treated intraluminally with mepacrine and PMA $\left(10^{-4}\right.$ and $10^{-5} \mathrm{M}$, respectively) was $0.89 \pm 0.04(n=4)$, compared with $0.81 \pm 0.07(n=6)$ in ligated intestinal segments treated only with PMA $\left(10^{-5} \mathrm{M}\right)$. The volume/length ratios in control loops treated with mepacrine alone $(0.18 \pm 0.05, n=2)$ or mepacrine and 4- $\alpha$-phorbol $(0.24 \pm 0.17, n=4)$ at the same concentrations were significantly less $(P \leq 0.01$ for both).

\section{Discussion}

In this report, we present data suggesting a role for the activation of PK-C in intestinal ion secretion. PK-C has previously been identified in rat small intestine smooth muscle (23), and both de Jonge (16) and we, as reported here, have detected the presence of PK-C in isolated intestinal epithelial cell preparations. Since the enzyme co-elutes with the receptor for phorbol esters during purification to various extents $(20,24-26)$, and since phorbol esters directly stimulate the enzyme (14), we used these tumor promoters as probes to examine the involvement of PK-C in intestinal ion secretion. Our in vivo data indicating net intestinal secretion with micromolar concentrations of the active, but not the inactive analogues of the phorbol esters, suggest a role for the activation of PK-C in causing intestinal secretion. The concentration dependence seen in our studies for secretion is 1-2$\mathbf{M}$ logs higher than in other secretory systems using isolated cell preparations $(13,27,28)$, and in some systems $(29,30)$, stimulation of processes involving secretion has been seen with nanomolar concentrations. However, in some systems in which large numbers of cells are necessary (31), high concentrations of phorbol esters have been required, probably to overcome the large nonspecific binding due to lipid partitioning. Such nonspecific binding may similarly account for the relatively high phorbol ester concentrations needed for secretory effects in our ligated porcine intestinal segments in vivo.

Whether or not PK-C stimulation alone is sufficient to elicit measurable net secretion in vivo is uncertain at present. Intestinal secretion has been stimulated by products released during an inflammatory response. Musch et al. have shown that bradykinin added in vitro to the serosal surface of rabbit or guinea pig ileum or rabbit colon has potent secretory effects, with chloride secretion being seen at concentrations as low as $10^{-10} \mathrm{M}$ (32). The effects of bradykinin were linked to the intracellular release of arachidonic acid, which may be metabolized through one of two pathways: either the cyclooxygenase pathway with the production of prostaglandins and related substances (such as prostacyclin and thromboxanes), or by the lipoxygenase pathway to produce hydroperoxyeicosatetraenoic acid or hydroxyeicosatetraenoic acid and leukotrienes. Notably, hydroperoxyeicosatetraenoic acid and hydroxyeicosatetraenoic acid have been shown to cause chloride secretion in vitro in rabbit colon but not rabbit ileum (33). In addition, prostaglandins of the E series (especially prostaglandin $\mathrm{E}_{2}$ ) are known to be secretagogues (34). In our studies, there was no inflammation seen in the intestinal tissue at $\mathbf{3 0}$ min or at $16 \mathrm{~h}$, times at which a secretory response was measured. The minimum increase in neutrophils noted histologically at 5 $h$ is of doubtful significance, especially since mepacrine, which inhibits phospholipase A2, and thus arachidonic acid release, did not alter the secretory response we observed with PMA at $5 \mathrm{~h}$. This dose of mepacrine has previously been shown to inhibit 
the response to bradykinin in vitro by $>80 \%$ (32). These findings suggest that products of the inflammatory reaction do not contribute to the secretory response we observed with the phorbol esters.

The effect of the phorbol esters on the electrolyte content of intestinal fluid and the rapid onset of net water accumulation suggest a direct role for PK-C activation in the transport of several ions, perhaps secondary to phosphorylation of one or more membrane ion transporters. This hypothesis is supported by the observation that treatment of certain cell types with the $\beta$ analogues of the phorbol esters results in a decrease in PK-C activity in the cytosolic fraction $(27,35)$ and an increase in the membrane fraction (36). In our studies, the major ions present in the intestinal fluid were sodium and chloride, suggesting primarily an impact on neutral sodium chloride absorptive mechanisms. The net accumulation of potassium could reflect a change in paracellular transport secondary to a loosening of the intestinal epithelial cell tight junctions. Alternatively, the accumulation of potassium could reflect secretion by calcium-activated potassium channels (37). More detailed studies examining changes in ion transport due to phorbol esters in vitro and electron microscopic examinations of epithelium treated with phorbol esters will be necessary to evaluate these possibilities.

In summary, these results demonstrate PK-C activity and specific phorbol ester binding in porcine jejunal epithelial cells, and suggest that direct activation of PK-C by phorbol esters causes net intestinal ion secretion in piglet jejunum in vivo. Further studies evaluating the interaction of PK-C stimulation with previously described intestinal secretagogues that act by the cyclic nucleotide-dependent and independent pathways should prove fruitful in advancing our understanding of the molecular basis for alterations in ion transport.

\section{Acknowledgments}

We would like to thank Ms. Lynn Haboush and Ms. Susan Davis for their help in the preparation of this manuscript.

This work was supported in part by the National Institutes of Health (NIH) training grant T32A107046, NIH grant GM3-1184, and by The Rockefeller Foundation.

\section{References}

1. Moss, J., D. L. Burns, J. A. Hsia, E. L. Hewlett, R. L. Guerrant, and M. Vaughan. 1984. Cyclic nuçeotides: mediators of bacterial toxin action in disease. Ann. Intern. Med. 101:653-666.

2. Kennedy, D. J., R. N. Greenberg, J. A. Dunn, R. Abernathy, J. S. Ryerse, and R. L. Guerrant. 1984. Effects of Escherichia coli heatstable enterotoxin STb on intestines of mice, rats, rabbits and piglets. Infect. Immun. 46:639-643.

3. Bolton, J. E., and M. Field. 1977. Ca ionophore-stimulated ion secretion in rabbit ileal mucosa: relation to actions of cyclic $3^{\prime}, 5^{\prime}$-AMP and carbamylcholine. J. Membr. Biol. 35:159-173.

4. Frizzell, R. A. 1977. Active chloride secretion by rabbit colon: calcium-dependent stimulated by ionophore A23187. J. Membr. Biol. 35:175-187.

5. Isaacs, P. E. T., C. L. Corbett, A. K. Riley, P. C. Hawker, and L. A. Turnberg. 1976. In vitro behavior of human intestinal mucosa: the influence of acetylcholine on ion transport. J. Clin. Invest. 58:535542.

6. Hughes, S., G. Warhurst, L. A. Turnberg, N. B. Higgs, L. G. Giugliano, and B. S. Drasar. 1983. Clostridium difficile toxin-induced intestinal secretion in rabbit ileum in vitro. Gut. 24:94-98.
7. Donowitz, M., N. Asarkof, and G. Pike. 1980. Calcium dependence of serotonin-induced changes in rabbit ileal electrolyte transport. J. Clin. Invest. 66:341-352.

8. Cheung, W. Y. 1980. Calmodulin plays a pivotal role in cellular regulation. Science (Wash. DC). 207:19-27.

9. Powell, D. W. 1984. Enterotoxigenic diarrhea: mechanisms and prospects for therapy. Pharmacol. Ther. 23:407-416.

10. Powell, D. W., H. M. Berschneider, L. D. Lawson, and H. Martens. 1985. Regulation of water and ion secretion in intestine. In Microbial Toxins and Diarrhoeal Disease. D. E. Evered and J. Whelan, editors. Pitman, Publishing Ltd., London. 14-33.

11. de Jonge, H. R., and S. M. Lohman. 1985. Mechanisms by which cyclic nucleotides and other intracellular mediators regulate secretion. In Microbial Toxins and Diarrhoeal Disease. D. E. Evered and J. Whelan, editors. Pitman, London. 116-138.

12. Nishizuka, Y. 1984. Turnover of inositol phospholipids and signal transduction. Science (Wash. DC). 225:1365-1370.

13. Brown, E. M., J. Redgrave, and J. Thatcher. 1984. Effect of phorbol ester TPA on PTH secretion. FEBS (Fed. Eur. Biochem. Soc.) Lett. 175:72-75.

14. Castagna, M., Y. Takai, K. Kaibuchi, K. Sano, U. Kikkawa, and Y. Nishizuka. 1982. Direct activation of calcium-activated, phospholipiddependent protein kinase by tumor-promoting phorbol esters. J. Biol. Chem. 257:7847-7851.

15. Kuo, J. F., R. G. G. Anderson, B. C. Wise, L. Mackerlova, I. Salomonsson, N. L. Brackett, N. Katch, M. Shoji, and R. W. Wrenn. 1980. Calcium-dependent protein kinase: widespread occurrence in various tissues and phyla of the animal kingdom and comparison of effects of phospholipid, calmodulin, and trifluoperazine. Proc. Natl. Acad. Sci. USA. 12:7039-7043.

16. de Jonge, H. R. 1983. Novel substrate proteins for cyclic nucleotide, calcium, and phospholipid-dependent kinases in the intestinal brush border. Gastroenterol. Clin. Biol. 7:504. (Abstr.)

17. Nishizuka, Y. 1984. The role of protein kinase $C$ in cell surface signal transduction and tumor promotion. Nature (Lond.). 308:693-698.

18. Weiser, M. M. 1973. Intestinal epithelial cell surface membrane glycoprotein synthesis. J. Biol. Chem. 248:2356-2541.

19. Kimmich, G. A. 1970. Preparation and properties of mucosal epithelial cells isolated from small intestine of the chicken. Biochemistry. 9:3659-3668.

20. Uchida, T., and C. R. Filburn. 1984. Affinity chromatography of protein Kinase C-Phorbol ester receptor on polyacrylamide-immobilized phosphatidylserine. J. Biol. Chem. 259:12311-12314.

21. Allen, W. M. 1950. A simple method for analyzing complicated absorption curves, of use in the colorimetric determinations of urinary steroids. J. Clin. Endocrinol. 10:71-83.

22. Blumberg, P. M. 1980. In vitro studies on the mode of action of the phorbol esters, potent tumor promoters. Crit. Rev. Toxicol. 8:153197 ,

23. Minakuchi, R., Y. Takai, B. Yu, and Y. Nishizuka. 1981. Widespread occurrence of calcium-activated, phospholipid-dependent protein kinase in mammalian tissues. J. Biochem. 89:1651-1654.

24. Niedel, J. E., L. J. Kuhn, and G. R. Vanderbank. 1983. Phorbol diester receptor copurifies with protein kinase C. Proc. Natl. Acad. Sci. USA. 80:36-40.

25. Kikkawa, V., Y. Takai, R. M. Tanaka, and N. Nishizuka. 1983. Protein kinase $\mathrm{C}$ as a possible receptor protein of tumor-promoting phorbol esters. J. Biol. Chem. 258:11442-11445.

26. Parker, P. J., S. Stable, and M. D. Waterfield. 1984. Purification to homogenicity of protein kinase $\mathrm{C}$ from bovine brain-identity with the phorbol ester receptor. EMBO (Eur. Mol. Biol. Organ.) J. 3:953-959.

27. Wooten, M. W., and R. W. Wrenn. 1984. Phorbol ester induces intracellular translocation of phospholipid $/ \mathrm{Ca}^{+2}$-dependent protein kinase and stimulates amylase secretion in isolated pancreatic acini. FEBS (Fed. Eur. Biochem. Soc.) Lett. 171:183-186.

28. de Pont, J. J. H. H. M., and A. M. M. Fleuren-Jakobs. 1984. Synergistic effect of A23187 and a phorbol ester on amylase secretion 
from rabbit pancreatic acini. FEBS (Fed. Eur. Biochem. Soc.) Lett. 170: 64-68.

29. Yamanishi, J., Y. Takai, K. Kaibuchi, K. Sano, M. Castagna, and Y. Nishizuka. 1983. Synergistic functions of phorbol ester and calcium in serotonin release from human platelets. Biochem. Biophys. Res. Commun. 112:778-786.

30. Sando, J., M. L. Hilfiker, M. J. Piacentini, and T. M. Laufer. 1982. Identification of phorbol ester receptors in T-cell growth factorproducing and -nonproducing EL4 mouse thymoma cells. Cancer Res. 42:1676-1680.

31. Garrison, J. C., D. J. Johnson, and C. P. Campanile. 1984. Evidence for the role of phosphorylase kinase, protein kinase $\mathrm{C}$, and other $\mathrm{Ca}^{++}$sensitive protein kinases in the response of hepatocytes to angiotensin II and vasopressin. J. Biol. Chem. 259:3283-3292.

32. Musch, M. W., J. F. Kachur, R. J. Miller, and M. Field. 1983. Bradykinin-stimulated electrolyte secretion in rabbit and guinea pig intestine. J. Clin. Invest. 71:1073-1083.
33. Musch, M. W., R. J. Miller, M. Field, and M. I. Siegel. 1982. Stimulation of colonic secretion by lipoxygenase metabolites of arachidonic acid. Science (Wash. DC). 217:1255-1256.

34. Field, M., M. W. Musch, and J. S. Stoff. 1981. Role of prostaglandins in the regulation of intestinal electrolyte transport. Prostaglandins. 21(Suppl.):73-79.

35. Kraft, A. S., W. B. Anderson, H. L. Cooper, and J. J. Sando. 1982. Decrease in cytosolic calcium/phospholipid-dependent protein kinase activity following phorbol ester treatment of EL4 thymoma cells. J. Biol. Chem. 257:13193-13196.

36. Kraft, A. S., and W. B. Anderson. 1983. Phorbol esters increase the amount of $\mathrm{Ca}$, phospholipid-dependent protein kinase associated with plasma membrane. Nature (Lond.). 301:621-623.

37. Peterson, O. H., and Y. Maruyama. 1984. Calcium-activated potassium channels and their role in secretion. Nature (Lond.). 307:693696. 